\title{
Creativity and Entrepreneurial Efforts in an Emerging Economy
}

\author{
Quan Hoang Vuong \\ Université Libre de Bruxelles \\ Nancy K. Napier \\ Boise State University and Aalborg University \\ Thu Hang Do \& Thu Trang Vuong \\ Vuong E Associates
}

\begin{abstract}
While much research has focused on entrepreneurship and creativity in developed economies, the notions of both topics are still embryonic in many emerging economies. This paper focuses on entrepreneurs in one such economy, Vietnam, to understand the perceptions of entrepreneurs about the role that innovation and creativity may play in their decisions to start entrepreneurial ventures. This is important because before reaping benefits from entrepreneurship, entrepreneurs need to decide when and on what conditions they start based on their calculations of required resources and predictions of likely outcomes. The research also sought to understand how "creativity," broadly applied ("innovation" and "creative performance"), affects the ways that entrepreneurs think about and anticipate their own success and decisions. In essence, the study suggests that the higher the entrepreneur's creativity is, the more likely she or he is to start a new business and believe success will result. Future research could examine whether history, industry and geographic location matter in entrepreneurs' perceptions as well as whether transition/emerging economies like Vietnam may have different views altogether about the two key concepts.
\end{abstract}

Entrepreneurship has been long considered a critical component of market economies and increasingly in transition and emerging economies. Entrepreneurial processes nurture emerging business ideas, amass resources for implementing them, create jobs and help transform resources into goods and services for society's consumption. Also, as Schumpeter pointed out, the creative performance by entrepreneurs is the cause of economic change (Frank 1988). So at the heart of the entrepreneurship system lie "creativity," and its variants: "creative performance" "innovation" and "technological progress" for example.

While much research has focused on entrepreneurs and creativity in developed economies, the whole notion is still nascent in emerging economies. This paper focuses on entrepreneurs in one such economy, Vietnam, to understand the perceptions of entrepreneurs about the role that innovation and creativity may play in their own entrepreneurial ventures

Correspondence should be addressed to Quan Hoang Vuong, Centre Emile Bernheim, Université Libre de Bruxelles, Brussels 1050, Belgium. Email: qvuong@ulb.ac.be. and success. Vietnam is a good economy to study because the ideas are still new enough that research can begin tracking how they develop and evolve, and it could be a place where new models of entrepreneurship development and its research may occur.

In particular, the paper aims to communicate results from research on the perception of Vietnamese entrepreneurs about the likelihood of success/failure and decisions on their own entrepreneurial attempts. This is important because before reaping benefits from entrepreneurship, entrepreneurs need to decide when and on what conditions they start based on their calculations of required resources and predictions of likely outcomes. The research also sought to understand how "creativity," broadly applied ("innovation" and "creative performance") affects the ways that entrepreneurs think about and anticipate their own success and decisions.

The paper has four main parts. It begins with a brief literature review examining key variables in subsequent modeling efforts. The next part presents the statistical model employed in investigating research questions. Third, the 
paper describes the data set and analysis. The article closes with a discussion of key insights and suggestions for future research.

\section{Background}

Creativity has become key in strategic management and a rich theme of research (Runco 2014), although the definition for it is not universally standard (Runco \& Jaeger 2012). For entrepreneurs, creativity constitutes a major dimension to define strategic entrepreneurship that helps deal with limitation entrepreneurial firms usually face in terms of longer-term implementation of business plan (Ireland, Hitt \& Sirmon 2003; Napier \& Vuong, 2013). It is the nature of the complex social system of entrepreneurship that makes creativity both elusive and difficult to take advantage of (Woodman, Sawyer, \& Griffin, 1993). Entrepreneurs' creative performance can generally be classified into radical and nonradical (or incremental) types (Jaussy \& Randel, 2014). The former focuses on "novelty" of products, services and business processes (including management structure) while the latter tends to emphasize continuous improvement that meets market demands thanks to relevance to the consumer, more competitive products, and cost reduction. The two types require different types of resources and structure of management in terms of commercialization of creativity (Frank, 1998), therefore our subsequent analysis controlled for the difference to explore changing impacts of other factors on entrepreneurs' perceptions about the outcome of their attempts.

Entrepreneurs need networks, social and professional, to support their performance through combining skills, experiences and creativity capacity (Basadur \& Basadur, 2013; Basadur, Gelade, \& Basadur, 2014). In entrepreneurs' networking efforts (Runco, 1994; Perry-Smith \& Shalley , 2003), the communication of ideas and information are likely to help improve creativity (Perry-Smith \& Shalley, 2003; Runco, 2014; Vuong \& Napier, 2014b). Harryson (2008) also introduced "strategic navigation" through the use of socalled transformation networks, and articulated the concept of "networked innovation." In light of this, social networks will subsequently enter our analytical models as an element that possibly exerts influence on entrepreneurs' decisions and perceived likelihood of success.

Fillis and Rentschler (2010) suggested that entrepreneurship is subject to randomness, uncertainty, and ambiguity, which can be better understood when put into wider socio-economic contexts. Also, creativity is a process embedded in entrepreneurship, linked to entrepreneurs' personalities and cognitive styles (Ward, 2004; Woodman, Sawyer, \& Griffin, 1993). In addition, for both creativity and entrepreneurial efforts to take off, entrepreneurs require patience (Fillis \& Rentschler, 2010; Napier, Vu, \& Vuong, 2012; Woodman, Sawyer, \& Griffin, 1993).

Although for developed economies the coupling of entrepreneurship and creativity has been established and studied, both theoretically and empirically, the policy frameworks that focus on entrepreneurship and creativity still lack cohesion and need further empirical evidence (Audretsch \& Link, 2012). The issue is even more acute in developing economies. Developing economies, especially those in stages of transition, often face a lack of innovation, which can lead to weak and inefficient entrepreneurship waves, inefficiencies, and a waste of scarce innovation “resources" (Vuong \& Napier, 2014).

In an emerging economy like Vietnam, the association of creativity and socio-cultural factors in determining business efficiency is verified, and stronger influence of creativity is confirmed for a firm in their entrepreneurial stage (Vuong, Napier, \& Tran, 2013). Therefore, it is more efficient to examine determinants of entrepreneurship outcomes with presence of a control variable such as "creativity" factor (radical and non-radical). This is particularly practical as there is strong evidence of short-term opportunity-based value creation processes while theoretically it is possible to say that that novelty and relevance/usefulness may have different degrees of influence on entrepreneurial performance as well as require more that serendipitous opportunities (Vuong \& Napier, 2014).

This background research points to several key factors (i.e., predictor variables) that may relate to outcomes from entrepreneurial efforts in Vietnam's emerging market. Those variables include financial constraint, assessment of socioeconomic conditions, an entrepreneur's involvement in social networks, work experience (skill-related), patience, and selfreported degree of creative performance. Entrepreneurship outcomes, which will serve as dependent ("response") variables in our investigation, include: perceived chance of success, how decisive ("soon") they are in making an actual entrepreneurial attempt, and time lag to their first actual revenue.

\section{Research Framework and Questions}

The present investigation of the likely effects of the predictor (independent) variables on entrepreneurship outcomes employed the analytical framework of baseline-category logits (BCL). The BCL modeling with a full description of its technical treatments are provided in Agresti (2013). Expectations for the present investigation were based on the following treatment of the data and independent variables. 


\section{The BCL Method}

The BCL method employed in this study is estimated as a multivariate generalized linear model (GLM) taking the form:

$$
\mathbf{g}\left(\boldsymbol{\mu}_{i}\right)=\mathbf{X}_{i} \boldsymbol{\beta},
$$

where, $\boldsymbol{\mu}_{i}=\mathrm{E}\left(\mathbf{Y}_{i}\right)$, corresponding to $\mathbf{y}_{i}=\left(y_{i 1}, y_{i 2}, \ldots\right)^{\prime}$; row $h$ of the model matrix $\mathbf{X}_{i}$ for observation $i$ contains values of independent variables for $y_{i h}$.

Following this method, as $\pi_{i}(\mathbf{x})=P(Y=j \mid \mathbf{x})$ represent a fixed setting for predictor variables, with $\sum_{i} \pi_{i}(\mathbf{x})=1$, count data are distributed over $J$ categories of $Y$ as multinomial with corresponding probabilities $\left\{\pi_{1}(\mathbf{x}), \ldots, \pi_{i}(\mathbf{x})\right\}$. The BCL model aligns each response (dependent) variable with a baseline category: $\ln \left[\boldsymbol{\pi}_{i}(\mathbf{x}) /\right.$ $\left.\boldsymbol{\pi}_{I}(\mathbf{x})\right]$, with $j=1, \ldots, J-1$.

As $\ln \left[\pi_{a}(\mathbf{x}) / \pi_{b}(\mathbf{x})\right]=\ln \left[\pi_{a}(\mathbf{x}) / \pi_{l}(\mathbf{x})\right]-\ln \left[\pi_{b}(\mathbf{x}) /\right.$ $\left.\boldsymbol{\pi}_{I}(\mathbf{x})\right]$, the set of response probabilities from multinomial logits $\left\{\boldsymbol{\pi}_{i}(\mathbf{x})\right\}$, can be computed from the formula:

$$
\boldsymbol{\pi}_{j}(\mathbf{x})=\frac{\exp \left(\alpha_{j}+\beta_{j}^{\mathrm{T}} \mathbf{x}\right)}{1+\sum_{h}^{J-1} \exp \left(\alpha_{h}+\beta_{h}^{\mathrm{T}} \mathbf{x}\right)} .
$$

The categorical variables used in our models are both dichotomous (e.g., the control variate "inno" and "diff" takes value of "yes" or "no") and multinomial (e.g., factor "econdf" takes "fav", "somewhat" or "unfav"). Their coded names and values are described in the corresponding data set in the data section. A relevant example of real-world analysis employing actual survey data was given in Vuong (2015).

\section{Research Questions}

RQ1. What are the relationships between entrepreneurs' perceived economic conditions, financial constraints, and degree of creativity and decisions by the same entrepreneurs about whether to pursue entrepreneurial venture/effort, controlling for "creativity"?

RQ2. What, if any, impact do work experience, strategic patience, and degree of creativity appear to have on the likelihood of success, as perceived by extant/prospective entrepreneurs?

RQ3. To what extent do work skills, involvement in social entrepreneurship networks, and creativity relate to an entrepreneur's ability to estimate time to first dollar revenue?
The results reported for investigation of RQ1-RQ3 were estimated using software R. All relevant statistics are provided in corresponding result tables. Subsequent empirical results then helped establish relationships between polytomous response variables and discrete (multinomial or binomial) explanatory variables. Afterwards, specific probabilities upon specific "events" of hypothetical influence were computed.

\section{Method}

\section{Participants}

A survey was conducted through a series of conferences and meetings that were organized in five economic centers in Vietnam (Hanoi, Ho Chi Minh City, Da Nang, Buon Ma Thuot, Can Tho) through the Vietnamese Federation of the Youth and Students, Trung Nguyen Coffee Group, the Center for Business Study and Assistance, under a joint initiative on youth entrepreneurship. Participating entrepreneurs who were willing to share their thinking and experience were given questionnaires by authorized personnel. Answers were collected only after participants had completed their participation and had been well informed.

An estimated number of 50,000 entrepreneurs attended these events, and about 10,000 were randomly approached during the survey period, from March to May 2015. The data sample contained 3,071 observations, answered in full or in part (thus the actual relevant data subset for each estimation is smaller than the total number of observations received). The data were categorical by both research nature and design. Each research question dealt with part of the full data set. Thus, the following discussion examines each subset of data for a specific set of research question (i.e., RQ1-3), including with proper explanations, after adjusting for missing data.

Data for RQ1. The data subset for RQ1 contains 2,494 responses that were used to estimate the impacts of entrepreneurs' perception about economic conditions ("econdf"), financial constraints ("finance") and degrees of creativity ("inno" or "diff") on their decisions to start business or not. This data set is provided in Table 1.

The factor "econdf" uses categorical values of "fav" (favorable), "somewhat" (somewhat favorable) and "unfav" (unfavorable) to represent the perception by the surveyed entrepreneur about how favorable the socioeconomic conditions are for their current/coming attempt. The issue presented by the group "finance" deals with only two states "shortage" and "noshortage"; the answer basically suggests that an entrepreneur feels constrained by the availability of finance.

It is noteworthy that "creativity" here is defined as taking two different values for distinct states of creativity. Value 
"inno" represents a highly creative assessment as shown by radical innovation; and "diff" a somewhat creative, enough to show differences in products, services, or business processes that help bring value to an entrepreneurial business but not with substantial novelty. Each of these two factors takes value of "yes" or "no." The values of factor "creativity" serve to be a control variate for outcome.

The last factor is "startplan" representing when the respondent estimates he or she will start his/her own business, with four categorical values: "a" (currently operating one), "b" (within the next 12 months), "c" (only with favorable conditions), "d" (will not start). This factor serves to be response variable in our model, and the probability of event will be computed against independent categorical variables described above, following empirical modeling employing data given in Table 1.

Likewise, the data subset for modeling conditional probabilities of responses (entrepreneurial decisions) following socioeconomic conditions, availability of finance and control variate value of "diff" is constructed and provided in Table A1, with "diff" taking value of either "yes" or "no", the same way Table 1 controls for radical creativity ("inno").

Data for RQ2. The data subset for RQ1 (provided in Table 2) contained 2,759 responses to estimate the impacts of past entrepreneurial attempt ("starthis"), patience ("tforstart"), and creativity on perceived likelihood of success ("chance"). In Table 2, factor "starthis" took three categorical values of "running" (currently operating one), "dropped" (used to operate one), and "notyet" (no startup experience); factor "tforstart" evaluates an entrepreneur's patience in this particular attempt, taking three categorical values of "less12" (<12 months), "b1224" (from 12 to 24 months), and "g24" (> 24 months, if so required).

An entrepreneur's self-evaluation of likelihood of success ("chance") used one of the three values: "high" (>80\%), "med" $(50-80 \%)$, "low" $(<50 \%)$, and serves as the response variable in the model, where factor creativity remains as the control variate, for state of "inno" or "diff" (each taking value of "yes"/"no").

Table 2 suggests that 2000 entrepreneurs (out of 2759 ), or nearly $72.5 \%$, planned to be patient with their entrepreneurial attempts, giving themselves more than 24 months (until success), and 53\% evaluated their chance to be 50-80\% ("med": 1461 responses). In the same way, the table in Table A2 provides the data subset for RQ2 with control variate "diff" instead of "inno."

Data for RQ3. The subset for RQ3 (in Table 3) contained 2,714 data points, involving answers about previous work experience of the respondent, factor "job," with 3 values "adhrm" (admin/HRM), "tech" (experience with technical skills: finance, accounting, production and operations, marketing, and so on), and "none"(no experience).
TABLE 1 (Data for RQ1)

Contingency table of entrepreneurial decisions following socioeconomic conditions, availability of finance, with control variate of "inno"

\begin{tabular}{|c|c|c|c|c|c|c|}
\hline \multirow{2}{*}{ "condf" } & \multirow{2}{*}{ "finance" } & \multirow{2}{*}{ "inno" } & \multicolumn{4}{|c|}{ "startplan" } \\
\hline & & & "a" & "b" & "c" & "d" \\
\hline \multirow{4}{*}{ "fav" } & \multirow{2}{*}{ "noshortage" } & "no" & 8 & 14 & 25 & 11 \\
\hline & & "yes" & 44 & 54 & 43 & 16 \\
\hline & \multirow{2}{*}{ "shortage" } & “no" & 4 & 12 & 17 & 3 \\
\hline & & "yes" & 28 & 28 & 34 & 6 \\
\hline \multirow{4}{*}{ "somewhat" } & \multirow{2}{*}{ "noshortage" } & “no" & 19 & 60 & 257 & 104 \\
\hline & & "yes" & 77 & 162 & 251 & 61 \\
\hline & \multirow{2}{*}{ "shortage" } & “no” & 10 & 39 & 188 & 35 \\
\hline & & “yes" & 64 & 121 & 210 & 30 \\
\hline \multirow{4}{*}{ “unfav" } & \multirow{2}{*}{ "noshortage" } & “no" & 9 & 15 & 85 & 49 \\
\hline & & "yes" & 10 & 18 & 54 & 21 \\
\hline & \multirow{2}{*}{ "shortage" } & “no" & 2 & 5 & 72 & 25 \\
\hline & & "yes" & 11 & 12 & 58 & 13 \\
\hline
\end{tabular}

Notes: Sample size: 2494; refer to "Data for RQ1" for the meaning of each variable.

Table 2 (Data for RQ2)

Contingency table of perceived likelihood of success following past startup experience, strategic patience, with control variate value of "inno"

\begin{tabular}{|c|c|c|c|c|c|}
\hline \multirow{2}{*}{ "starthis" } & \multirow{2}{*}{ "tforstart" } & \multirow{2}{*}{ "inno" } & \multicolumn{3}{|c|}{ "chance" } \\
\hline & & & "bigh" & "low" & "med" \\
\hline \multirow{6}{*}{ "dropped" } & \multirow{2}{*}{ “b1224” } & "no" & 19 & 23 & 53 \\
\hline & & "yes" & 39 & 17 & 91 \\
\hline & \multirow{2}{*}{ “g24” } & "no" & 118 & 61 & 225 \\
\hline & & "yes" & 176 & 50 & 246 \\
\hline & \multirow{2}{*}{ "less12" } & "no" & 6 & 10 & 15 \\
\hline & & "yes" & 16 & 8 & 29 \\
\hline \multirow{6}{*}{ "notyet" } & \multirow{2}{*}{ “b1224” } & "no" & 15 & 16 & 43 \\
\hline & & “yes" & 24 & 14 & 67 \\
\hline & \multirow{2}{*}{ “g24” } & "no" & 101 & 79 & 171 \\
\hline & & “yes" & 110 & 27 & 148 \\
\hline & \multirow{2}{*}{ "less12" } & "no" & 3 & 7 & 15 \\
\hline & & "yes" & 7 & 9 & 17 \\
\hline \multirow{6}{*}{ "running" } & \multirow{2}{*}{ “b1224” } & "no" & 7 & 4 & 21 \\
\hline & & "yes" & 31 & 7 & 67 \\
\hline & \multirow{2}{*}{ "g24" } & "no" & 60 & 13 & 68 \\
\hline & & "yes" & 167 & 24 & 156 \\
\hline & \multirow{2}{*}{ "less12" } & "no" & 2 & 4 & 6 \\
\hline & & “yes" & 16 & 8 & 23 \\
\hline
\end{tabular}

Notes: Sample size: 2759; refer to "Data for RQ2" for the meaning of each variable. 
An entrepreneur was assessed in terms of activeness in social network of entrepreneurs (both extant and prospective), through factor "member," taking one of three values: "all" (many or all networks/societies), "some" (participating in several networks), and "none."

Response variables were "tot1strev" (time needed for the entrepreneurial operation to receive the first revenue), which had values of: "a" (currently generating revenue), "b" (within 12 months), and "c" (uncertain).

The model has the same control variate factor "creativity" with Table 3 showing variable "inno" (radical innovation) and Table A3 showing "diff" (incremental innovation).

\section{Estimations and Results}

\section{Radical Creativity That Counts}

Entrepreneurs in ongoing ventures depend upon more radical creativity, whereas those who have not started a venture see financial constraints as more critical. The first set of results considering the problems stated in RQ1 is reported in Table 4. All estimated coefficients were statistically significant, with $\mathrm{p}$-value $<.01$.

Table 4 suggests that entrepreneurs' perception about socio-economic conditions, financial constraint, and degree of creative performance all together relate to their subjective plan of making an entrepreneurial attempt. To have a deeper understanding of the results, the following set of stylized facts were constructed from the coefficients with associated conditions as stated by the BCL model given in equations RQ1.1-1.3.

\begin{tabular}{|c|c|}
\hline $\begin{array}{c}\ln \left(\frac{\pi_{a}}{\pi_{d}}\right)=-2.334+1.739 \text { favEcondf }+0.744 \text { swEcondf } \\
+0.487 \text { shortFin }+1.779 \text { yesInno }\end{array}$ & Eq. (RQ1.1) \\
\hline \begin{tabular}{c}
$\ln \left(\frac{\pi_{b}}{\pi_{d}}\right)=-\begin{array}{c}1.537+1.615 \text { favEcondf }+1.148 \text { swEcondf } \\
+0.430 \text { shortFin }+1.302 \text { yesInno }\end{array}$ \\
\hline $\begin{array}{c}\ln \left(\frac{\pi_{c}}{\pi_{d}}\right)=0.528+0.227 \text { favEcondf }+0.433 \text { swEcondf } \\
+0.629 \text { shortFin }+0.387 \text { yesInno }\end{array}$
\end{tabular} & Eq. (RQ1.2) \\
\hline
\end{tabular}

Eq. (RQ1.1) indicates that radical innovation capacity exhibited the single largest effect on whether a respondent was currently running an entrepreneurial operation, with $\beta_{4}=1.779$ ( $p$-value $<0.0001$ ). In contrast to Eq. (RQ1.3) for those who tend to wait until the conditions become more favorable, the largest impact was from the issue of financial constraint, with $\beta_{3}=0.629$ ( $\mathrm{p}$-value $<0.0001$ ). For complete probability distributions over "events" to be observed, Table 5 was constructed from computed conditional probabilities
Table 3 (Data for RQ3)

Contingency table of lead time to first entrepreneurial revenue, following past experience, activeness in social networks, with control variate value of "inno"

\begin{tabular}{|c|c|c|c|c|c|}
\hline \multirow{2}{*}{ "job" } & \multirow{2}{*}{ "member" } & \multirow{2}{*}{ "inno" } & \multicolumn{3}{|c|}{ "totst1rev" } \\
\hline & & & $" a "$ & $" b "$ & "c" \\
\hline \multirow{6}{*}{ “adhrm” } & \multirow{2}{*}{ "all" } & "no" & 8 & 31 & 14 \\
\hline & & "yes" & 21 & 75 & 25 \\
\hline & \multirow{2}{*}{ "none" } & "no" & 16 & 99 & 113 \\
\hline & & "yes" & 29 & 87 & 57 \\
\hline & \multirow{2}{*}{ "some" } & "no" & 8 & 34 & 33 \\
\hline & & “yes" & 10 & 87 & 38 \\
\hline \multirow{6}{*}{ "none" } & \multirow{2}{*}{ "all" } & “no" & 2 & 15 & 22 \\
\hline & & “yes" & 7 & 32 & 24 \\
\hline & \multirow{2}{*}{ "none" } & "no" & 3 & 102 & 180 \\
\hline & & "yes" & 9 & 86 & 101 \\
\hline & \multirow{2}{*}{ "some" } & "no" & 4 & 36 & 37 \\
\hline & & "yes" & 9 & 42 & 37 \\
\hline \multirow{6}{*}{ "tech" } & \multirow{2}{*}{ "all" } & “no" & 18 & 38 & 21 \\
\hline & & "yes" & 64 & 147 & 31 \\
\hline & \multirow{2}{*}{ "none" } & “no" & 19 & 118 & 88 \\
\hline & & "yes" & 66 & 188 & 51 \\
\hline & \multirow{2}{*}{ "some" } & "no" & 17 & 56 & 35 \\
\hline & & "yes" & 61 & 122 & 41 \\
\hline
\end{tabular}

Notes: Sample size: N=2714; Refer to "Data for RQ3" for the meaning of each variable.

Table 4

Estimated coefficients for RQ1 with associated statistics

\begin{tabular}{|c|c|c|c|c|c|}
\hline \multirow[t]{2}{*}{ 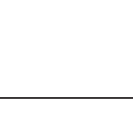 } & \multirow[t]{2}{*}{ intercept } & \multicolumn{2}{|c|}{ "condf" } & \multirow{2}{*}{$\begin{array}{l}\text { "finance" } \\
\text { "shortage" }\end{array}$} & \multirow{2}{*}{$\begin{array}{l}\text { "inno" } \\
\text { "yes" }\end{array}$} \\
\hline & & "fav" & "somewhat" & & \\
\hline $\operatorname{logit}(a \mid d)$ & $\begin{array}{l}-2.334^{+\ldots+m} \\
{[-9.465]}\end{array}$ & $\begin{array}{l}1.739^{\circ+1} \\
{[5.966]}\end{array}$ & $\begin{array}{l}0.744^{-\mu \prime} \\
{[3.226]}\end{array}$ & $\begin{array}{l}0.487^{\prime \prime \prime} \\
{[2.852]}\end{array}$ & $\begin{array}{l}1.779 \\
{[9.420]}\end{array}$ \\
\hline $\operatorname{logit}(b \mid d)$ & $\begin{array}{l}-1.537^{\prime} \\
{[-7.849]}\end{array}$ & $\begin{array}{l}1.615^{\prime \prime \prime} \\
{[6.127]}\end{array}$ & $\begin{array}{l}1.148^{+\cdots} \\
{[5.910]}\end{array}$ & $\begin{array}{l}0.430 \\
{[2.915]}\end{array}$ & $\begin{array}{l}1.302 \\
{[8.916]}\end{array}$ \\
\hline $\operatorname{logit}(\mathrm{c} \mid \mathrm{d})$ & $\begin{array}{l}0.528^{-3} \\
{[4.073]}\end{array}$ & $\begin{array}{c}0.227 \\
{[1.009]}\end{array}$ & $\begin{array}{c}0.433^{* *} \\
{[3.142]}\end{array}$ & $\begin{array}{l}0.629^{\prime+m} \\
{[4.959]}\end{array}$ & $\begin{array}{c}0.387^{\text {"* }} \\
{[3.181]}\end{array}$ \\
\hline
\end{tabular}

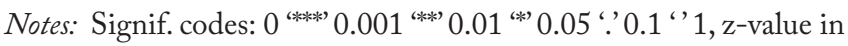
square brackets; baseline category for: "econdf": "unfav"; "finance": "noshortage"; and, "inno": "no". Residual deviance: 14.62 on 21 degrees of freedom. Refer to "Data for RQ1" for the meaning of each variable.

using coefficients of Eqs. (RQ1.1-3). In other words, entrepreneurs who have already begun a venture tended to see themselves as depending upon more radical creativity and those who have not begun see financial constraints as a more critical element in future action. 
Table 5

Probability distributions of entrepreneurial undertaking conditional upon perceived economic conditions, financial constraint, with control variate of creative performance ("inno")

\begin{tabular}{|c|c|c|c|c|c|c|c|c|}
\hline \multirow{3}{*}{$\begin{array}{l}\text { "startplan" } \\
\text { "inno" } \\
\text { "econdf"| "finance" }\end{array}$} & \multicolumn{4}{|c|}{ "running" (a) } & \multicolumn{4}{|c|}{ "soon" (b) } \\
\hline & \multicolumn{2}{|c|}{ "yes" } & \multicolumn{2}{|c|}{ "no" } & \multicolumn{2}{|c|}{ "yes" } & \multicolumn{2}{|c|}{ "no" } \\
\hline & "shortage" & "noshort" & "shortage" & "noshort" & "shortage" & "noshort" & "shortage" & "noshort" \\
\hline "somewhat" & 0.140 & 0.141 & 0.046 & 0.045 & 0.273 & 0.291 & 0.143 & 0.151 \\
\hline "unfav" & 0.119 & 0.118 & 0.034 & 0.032 & 0.155 & 0.163 & 0.071 & 0.071 \\
\hline “inno" & \multicolumn{2}{|c|}{ "yes" } & \multicolumn{2}{|c|}{ "no" } & \multicolumn{2}{|c|}{ "yes" } & \multicolumn{2}{|c|}{ "no" } \\
\hline "econdf"| "finance" & "shortage" & "noshort" & "shortage" & "noshort" & "shortage" & "noshort" & "shortage" & "noshort" \\
\hline "fav" & 0.321 & 0.275 & 0.529 & 0.447 & 0.055 & 0.089 & 0.132 & 0.210 \\
\hline "somewhat" & 0.515 & 0.450 & 0.674 & 0.581 & 0.072 & 0.118 & 0.137 & 0.223 \\
\hline
\end{tabular}

Note: Refer to "Data for RQ1" for the meaning of each variable.

Table 6

Propensity to start conditioned on value "diff", economic conditions and financial constraint

\begin{tabular}{|c|c|c|c|c|c|c|c|c|}
\hline \multirow{3}{*}{$\begin{array}{l}\text { "startplan" } \\
\text { "diff" } \\
\text { "econdf"| } \\
\text { "finance" }\end{array}$} & \multicolumn{4}{|c|}{ "running" (a) } & \multicolumn{4}{|c|}{ “soon" (b) } \\
\hline & \multicolumn{2}{|c|}{ “yes" } & \multicolumn{2}{|c|}{ "no" } & \multicolumn{2}{|c|}{ "yes" } & \multicolumn{2}{|c|}{ “no" } \\
\hline & "shortage" & "noshort" & "shortage" & "noshort" & "shortage" & "noshort" & "shortage" & "noshort" \\
\hline "fav" & 0.274 & 0.270 & 0.117 & 0.111 & 0.321 & 0.338 & 0.205 & 0.209 \\
\hline "somewhat" & 0.125 & 0.126 & 0.043 & 0.042 & 0.256 & 0.275 & 0.132 & 0.138 \\
\hline "unfav" & 0.111 & 0.110 & 0.034 & 0.032 & 0.149 & 0.158 & 0.068 & 0.068 \\
\hline “startplan" & \multicolumn{4}{|c|}{ "only with favorable conditions" (c) } & \multicolumn{4}{|c|}{ "not to start" (d) } \\
\hline "diff" & \multicolumn{2}{|c|}{ "yes" } & \multicolumn{2}{|c|}{ "no" } & \multicolumn{2}{|c|}{ "yes" } & \multicolumn{2}{|c|}{ "no" } \\
\hline $\begin{array}{l}\text { "econdf"| } \\
\text { "finance" }\end{array}$ & "shortage" & "noshort" & "shortage" & "noshort" & "shortage" & "noshort" & "shortage" & "noshort" \\
\hline "fav" & 0.345 & 0.295 & 0.516 & 0.428 & 0.06 & 0.097 & 0.162 & 0.252 \\
\hline "somewhat" & 0.545 & 0.477 & 0.662 & 0.562 & 0.074 & 0.122 & 0.163 & 0.258 \\
\hline "unfav" & 0.616 & 0.532 & 0.660 & 0.538 & 0.124 & 0.200 & 0.238 & 0.362 \\
\hline
\end{tabular}

Note: Refer to "Data for RQ1" for the meaning of each variable.

Table 5 suggests that even if facing financial shortage, the likelihood of currently operating an entrepreneurial firm was still reasonably high, approximately $29 \%$, when the positive business climate was felt and the entrepreneur was confident in his/her innovative capacity. Computed values also reconfirmed that prospective entrepreneurs tended to delay their attempts when socio-economic conditions are considered less favorable, or even decided not to start, as suggested by subtables (c) and (d). Effects of other factors on entrepreneurial decisions could be examined in similar ways, using subtables of Table 5 .

\section{Creativity Enhances Decision Making}

Empirical probabilities (see Fig. 1, constructed from Table B1) confirmed that entrepreneurs with significant innovation capacity tend to be more decisive in their entrepreneurial attempt than those without it. 
Table 7

Estimated impacts of past experience, strategic patience on likelihood of success evaluated by entrepreneurs, with the control variate of "inno"

\begin{tabular}{lcccccc}
\hline & \multirow{2}{*}{ Intercept } & \multicolumn{2}{c}{ "starthis" } & \multicolumn{2}{c}{ "tforstart" } & “inno" \\
\cline { 3 - 6 } & & "notyet" & "running" & "b1224" & "g24" & "yes" \\
\hline \multirow{2}{*}{ logit(high|low) } & $-0.562^{*}$ & -0.206 & $0.654^{* * *}$ & $0.498^{*}$ & $1.139^{* * * *}$ & $0.812^{* * * *}$ \\
\multirow{2}{*}{$\operatorname{logit}($ med|low) } & {$[-2.402]$} & {$[-1.469]$} & {$[3.781]$} & {$[1.973]$} & {$[5.129]$} & {$[6.330]$} \\
& $0.483^{*}$ & -0.218 & 0.300. & $0.657^{* *}$ & $0.665^{* * *}$ & $0.558^{* * * * *}$ \\
& {$[2.390]$} & {$[-1.701]$} & {$[1.799]$} & {$[3.012]$} & {$[3.441]$} & {$[4.687]$} \\
\hline
\end{tabular}

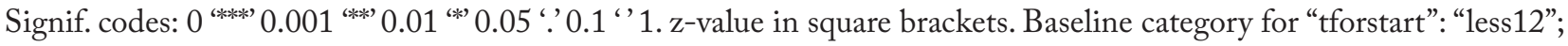
"starthis": "dropped"; and "inno": "no". Residual deviance: 14.31 on 24 d.f.

Notes: Refer to "Data for RQ2" for the meaning of each variable.

With the control variate of "inno" vs. "diff," described earlier, a comparison between entrepreneurs' behavior regarding this control provided further insight. For this task, empirical distribution of conditional probabilities for control variate value of "diff" were computed in Table 6, using estimated coefficients of logistic regressions reported in Table B2.

Early start and radical innovation. Entrepreneurs are more likely to use "early" starts when radical innovation capacity exists.

Figure 2 presents the differences of entrepreneurial attempts in cases of radical versus non-radical innovation capacity in two sets of empirical probabilities: i) of near-time entrepreneurial start (left); for those who only make attempts if seeing the context as favorable (right). In both graphs, both probability lines for "diff" and "creativity" move in the same direction. In Figure 2 (left) the "creativity" line is above the "difference" line, while the two lines swap positions in Figure 2 (right). In Figure 2 (left), for entrepreneurs who decide to start business "soon," the probability to make such decision drops from $>30 \%$ when "fav" to $<30 \%$ (less favorable), then to $15 \%$ when situation is unfavorable. In all circumstances, the probability of making an early start for those with radical innovation capacity is always higher. Figure 2 (right) suggests that the probability of "hesitation" (i.e., those who only act when seeing favorable conditions) for "non-radical" was higher than those with radical innovation. In addition, when the context changes from favorable ("fav") to unfavorable ("unfav") the level of hesitation jumps from 35\% to 60\% (for both groups).

\section{Innovation and Confidence}

Innovation relates positively to increasing the confidence of entrepreneurs in their startups.
The following estimations related to RQ2 use "chance" as response variable and 3 groups of predictor variables: "starthis", "tforstart", "inno" as seen in Table 7.

All coefficients in Table 7 showed statistical significance at the conventional level of $10 \%$, and 9 (out of 12) coefficients are significant at any level $(\mathrm{p}<0.01)$. The largest coefficient

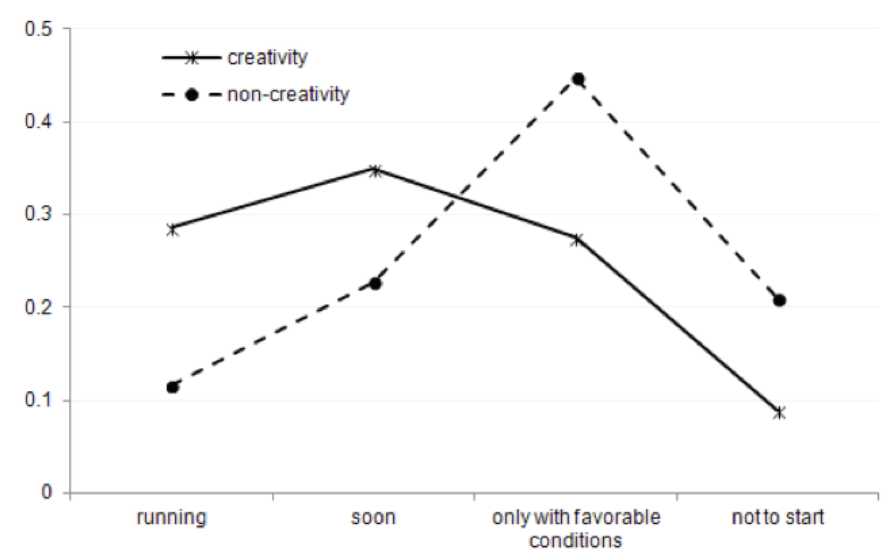

Figure 1. Propensity to start business for those with and without significant innovative capacity, holding equal the conditions of favorable economic conditions and no financial constraint.

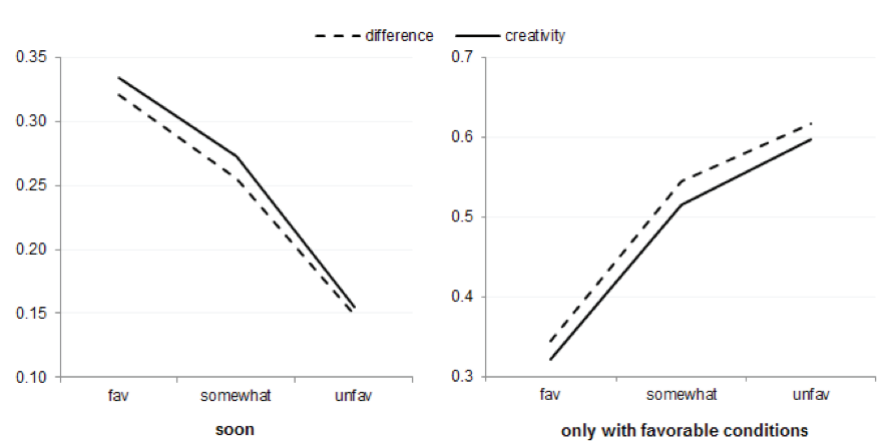

Figure 2. Probabilities of starting a venture with radical and non-radical creativity, facing financial shortage and seeing economic conditions as favorable (Table B3 data) 
Table 8

Distribution of probabilities of success for RQ2

\begin{tabular}{|c|c|c|c|c|c|c|}
\hline \multirow{3}{*}{$\begin{array}{l}\text { "chance" } \\
\text { "inno" } \\
\text { "tforstart"|"starthis" }\end{array}$} & \multicolumn{6}{|c|}{ "high" } \\
\hline & \multicolumn{3}{|c|}{ "yes" } & \multicolumn{3}{|c|}{ "no" } \\
\hline & "notyet" & "running" & “dropped” & "notyet" & "running" & "dropped" \\
\hline "g24" & 0.376 & 0.478 & 0.381 & 0.291 & 0.395 & 0.300 \\
\hline “b1224” & 0.242 & 0.327 & 0.246 & 0.178 & 0.257 & 0.185 \\
\hline “less12” & 0.242 & 0.339 & 0.251 & 0.168 & 0.256 & 0.179 \\
\hline "chance" & \multicolumn{6}{|c|}{ "med" } \\
\hline "inno" & \multicolumn{3}{|c|}{ “yes” } & \multicolumn{3}{|c|}{ "no" } \\
\hline "tforstart"|"starthis" & "notyet" & "running" & “dropped” & "notyet" & "running" & "dropped" \\
\hline “g24” & 0.509 & 0.460 & 0.524 & 0.509 & 0.490 & 0.531 \\
\hline “b1224” & 0.618 & 0.593 & 0.637 & 0.588 & 0.601 & 0.617 \\
\hline “less12” & 0.527 & 0.524 & 0.554 & 0.471 & 0.511 & 0.508 \\
\hline "chance" & \multicolumn{6}{|c|}{ "low" } \\
\hline "inno" & \multicolumn{3}{|c|}{ “yes” } & \multicolumn{3}{|c|}{ "no" } \\
\hline "tforstart"|"starthis" & "notyet" & "running" & “dropped” & "notyet" & "running" & "dropped" \\
\hline "g24” & 0.115 & 0.062 & 0.095 & 0.200 & 0.115 & 0.169 \\
\hline “b1224” & 0.14 & 0.080 & 0.117 & 0.234 & 0.142 & 0.198 \\
\hline “less12” & 0.231 & 0.137 & 0.195 & 0.361 & 0.233 & 0.313 \\
\hline
\end{tabular}

Note: Refer to "Data for RQ2" for the meaning of each variable.

observed in Table 7 is "g24" indicates a high importance of "patience", $\beta_{4}=1.139 \quad(p<0.0001)$. Empirical relationships (RQ2.1-2.2) are constructed from Table 7.

\begin{tabular}{|c|c|}
\hline $\begin{aligned} \ln \left(\frac{\pi_{\text {high }}}{\pi_{\text {low }}}\right)= & -0.562-0.206 \text { notyet }+0.654 \text { running } \\
& +0.498 \mathrm{~b} 1224+1.139 \mathrm{~g} 24+0.812 \text { yesInno }\end{aligned}$ & Eq. (RQ2.1) \\
\hline $\begin{aligned} \ln \left(\frac{\pi_{\mathrm{med}}}{\pi_{\text {low }}}\right)= & 0.483-0.218 \text { notyet }+0.300 \text { running } \\
& +0.657 \mathrm{~b} 1224+0.665 \mathrm{~g} 24+0.558 \text { yesInno }\end{aligned}$ & Eq. (RQ2.2) \\
\hline
\end{tabular}

These relationships enabled the computing of empirical distributions of probabilities of success against past work experience, patience, with control variate of "inno," as in Table 8.

Table 8 revealed a reasonable chance for a new entrepreneur, who believed in their innovation capacity, had "average" expectations, and was patient with the entrepreneurial attempt: $\sim 51 \%$ of success. In addition, "innovation" continued to exert its positive influence on increasing confidence of entrepreneurs in their startup projects, shown in trends of increasing probabilities of high success when moving from "no" to "yes"; in contrast, subjective probabilities of poor performance expectation showed a declining trend. Next Table 9 provides empirical distributions of values with the control variate "diff" (non-radical creativity) instead of "inno" (radical), using estimations provided in Table $\mathrm{C} 1$.

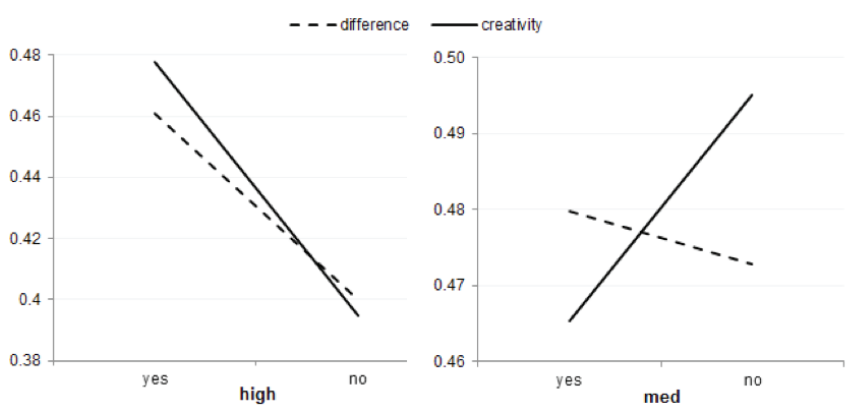

Figure 3. Likelihood of success (high vs. low) for those who are operating entrepreneurial firms, patient with business plan, with control variate values: "inno" (creativity) and "diff" (incremental innovation).

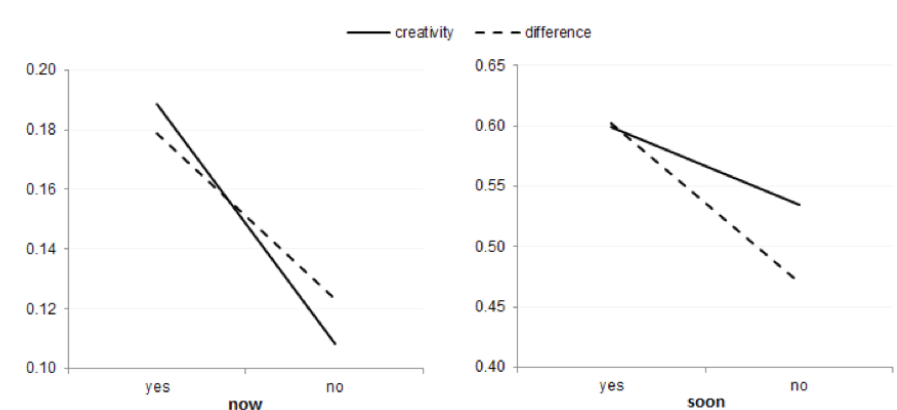

Figure 4. Probabilities of having revenues now or soon ("job"="adhrm"; "member"="all") 
Table 9

Distribution of probabilities of success for RQ2

\begin{tabular}{|c|c|c|c|c|c|c|}
\hline \multirow{3}{*}{$\begin{array}{l}\text { "chance" } \\
\text { "diff" } \\
\text { "tforstart"|"starthis" }\end{array}$} & \multicolumn{6}{|c|}{ "high" } \\
\hline & \multicolumn{3}{|c|}{ "yes" } & \multicolumn{3}{|c|}{ "no" } \\
\hline & "notyet" & "running" & "dropped" & "notyet" & "running" & "dropped" \\
\hline "g24" & 0.358 & 0.461 & 0.364 & 0.293 & 0.400 & 0.302 \\
\hline "b1224” & 0.233 & 0.316 & 0.237 & 0.185 & 0.266 & 0.191 \\
\hline "less12" & 0.231 & 0.325 & 0.239 & 0.168 & 0.257 & 0.177 \\
\hline "chance" & \multicolumn{6}{|c|}{ "med" } \\
\hline “diff” & \multicolumn{3}{|c|}{ “yes” } & \multicolumn{3}{|c|}{ "no" } \\
\hline "tforstart"|"starthis" & "notyet" & "running" & "dropped" & "notyet" & "running" & "dropped" \\
\hline "g24" & 0.531 & 0.475 & 0.538 & 0.493 & 0.468 & 0.506 \\
\hline “b1224” & 0.640 & 0.605 & 0.650 & 0.577 & 0.578 & 0.595 \\
\hline "less12" & 0.544 & 0.532 & 0.560 & 0.447 & 0.477 & 0.471 \\
\hline "chance" & \multicolumn{6}{|c|}{ "low" } \\
\hline “diff” & \multicolumn{3}{|c|}{ “yes” } & \multicolumn{3}{|c|}{ "no" } \\
\hline "tforstart"|"starthis" & "notyet" & "running" & "dropped" & "notyet" & "running" & "dropped" \\
\hline "g24" & 0.111 & 0.064 & 0.098 & 0.214 & 0.132 & 0.192 \\
\hline “b1224” & 0.127 & 0.079 & 0.113 & 0.238 & 0.156 & 0.214 \\
\hline "less12" & 0.225 & 0.143 & 0.201 & 0.385 & 0.266 & 0.352 \\
\hline
\end{tabular}

Note: Refer to "Data for RQ2" for the meaning of each variable.

Generally speaking, the tendency shown in Table 9 was similar to what emerged from the case of more radical innovation (i.e., control value of "inno"). However there were still some noteworthy differences, taking Figure 3 (drawn using computed data in Table $\mathrm{C} 2$ ) as an example.

Although the absolute change in probabilities is not large in these empirical observations, the control value "diff" tends to increase chance of success for extant entrepreneurs in both high- and medium-success clusters, while "inno" exerts only significant positive influence with cohort of higherperforming ones. Still the contribution of the creativity factor to an increase in the likelihood of success was not high, $<10$ percentage point at max.

\section{Creativity and Time to the First Revenue}

Creativity appeared to increase the chance of both extant and prospective entrepreneurs to generate revenue in a timely manner.

The last set of estimations and results for RQ3 worked with the response variable "tot1strev" and predictor variables of groups "job," "member," with the control variate of "inno" (Table 10) and "diff" (Table D1).

This question evaluated subjective probabilities of another kind of desired outcome for entrepreneurs: time to first revenue. In RQ3 estimations, factors such as work experience, activeness in social network and creativity all appeared to play positive roles in determining the outcome, since all estimates were highly significant and positive. The creativity factor was highly influential in both cases: currently generating revenue ("a") and in the next 12 months ("b"), although the past technical job experience ("tech") proves to be the single most influential in both logits: $\beta 2=2.145$ and 1.028 , respectively.

\begin{tabular}{|c|c|}
\hline $\begin{array}{c}\ln \left(\frac{\pi_{a}}{\pi_{c}}\right)=-3.264+1.228 \mathrm{adhm}+2.145 \text { tech }+0.841 \text { all } \\
+0.428 \text { some }+1.075 \text { yesInno }\end{array}$ & Eq. (RQ3.1) \\
\hline $\begin{array}{c}\ln \left(\frac{\pi_{a}}{\pi_{c}}\right)=-0.656+0.567 \mathrm{adhmr}+1.028 \text { tech }+0.491 \mathrm{all} \\
+0.219 \text { some }+0.633 \text { yesInno }\end{array}$ & Eq. (RQ3.2) \\
\hline
\end{tabular}

Next, empirical relationships (RQ3.1-3.2) enable the computing of conditional probabilities in Table 11.

The largest probability observed in Table 11 is 64.2\%, suggesting that a prospective entrepreneur without work experience and not confident in his/her creative performance would be unable to determine when the entrepreneurial attempt would bring in the first dollar revenue. The control variate was changed to "diff" (non-radical innovation) factor, using estimated coefficients in Table D1, to compute probabilities as in Table 12. 
Table 10

Estimations for RQ3, with control variate value "inno"="yes"

\begin{tabular}{|c|c|c|c|c|c|c|}
\hline \multirow{2}{*}{ 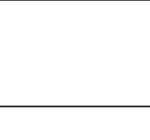 } & \multirow[t]{2}{*}{ Intercept } & \multicolumn{2}{|c|}{ "job" } & \multicolumn{2}{|c|}{ "member" } & \multirow{2}{*}{$\begin{array}{l}\text { "inno" } \\
\text { "yes" }\end{array}$} \\
\hline & & "adhrm" & "tech" & "all" & "some" & \\
\hline $\operatorname{logit}(a \mid c)$ & $\begin{array}{l}-3.264^{* * * *} \\
{[-15.815]}\end{array}$ & $\begin{array}{l}1.228 * * * \\
{[5.618]}\end{array}$ & $\begin{array}{l}2.145^{* * * *} \\
{[10.589]}\end{array}$ & $\begin{array}{l}0.841^{* * * *} \\
{[5.094]}\end{array}$ & $\begin{array}{l}0.428^{* *} \\
{[2.720]}\end{array}$ & $\begin{array}{l}1.075^{* * *} \\
{[7.568]}\end{array}$ \\
\hline $\operatorname{logit}(b \mid c)$ & $\begin{array}{c}-0.656^{* * * *} \\
{[-7.197]}\end{array}$ & $\begin{array}{l}0.567^{* * * *} \\
{[5.146]}\end{array}$ & $\begin{array}{l}1.028^{* * * *} \\
{[9.610]}\end{array}$ & $\begin{array}{l}0.491^{* * * *} \\
{[4.062]}\end{array}$ & $\begin{array}{c}0.219^{*} \\
{[2.071]}\end{array}$ & $\begin{array}{l}0.633^{* * *} \\
{[7.085]}\end{array}$ \\
\hline
\end{tabular}

Signif. codes: 0 (***) $0.001^{(* *)} 0.01^{(*)} 0.05$ '’0.1 ' 1 , z-value in square brackets ; baseline category : “job”=“none”, "member"="none", "inno"="no". Residual deviance: 37.57 on 24 d.f.

Note: Notes: Refer to "Data for RQ3" for the meaning of each variable.

Table 11

Probabilities of time to the first dollar revenue conditional upon past experience, social network membership and with radical creativity factor ("inno")

\begin{tabular}{|c|c|c|c|c|c|c|}
\hline \multirow{3}{*}{$\begin{array}{l}\text { "tot1strev" } \\
\text { "inno" } \\
\text { "job"|"member" }\end{array}$} & \multicolumn{6}{|c|}{ "now" } \\
\hline & \multicolumn{3}{|c|}{ "yes" } & \multicolumn{3}{|c|}{ "no" } \\
\hline & "all" & "some" & "none" & "all" & "some" & "none" \\
\hline "adhrm" & 0.189 & 0.157 & 0.123 & 0.108 & 0.086 & 0.064 \\
\hline "tech" & 0.289 & 0.25 & 0.204 & 0.183 & 0.152 & 0.118 \\
\hline "none" & 0.091 & 0.072 & 0.054 & 0.046 & 0.034 & 0.025 \\
\hline "tot1strev" & \multicolumn{6}{|c|}{ "soon" } \\
\hline "inno" & \multicolumn{3}{|c|}{ "yes" } & \multicolumn{3}{|c|}{ "no" } \\
\hline “job”|"member" & "all" & "some" & "none" & "all" & "some" & "none" \\
\hline “adhrm” & 0.599 & 0.575 & 0.555 & 0.534 & 0.487 & 0.447 \\
\hline “tech" & 0.581 & 0.579 & 0.583 & 0.574 & 0.546 & 0.522 \\
\hline "none" & 0.559 & 0.509 & 0.468 & 0.438 & 0.379 & 0.333 \\
\hline "tot1strev" & \multicolumn{6}{|c|}{ "not sure" } \\
\hline "inno" & \multicolumn{3}{|c|}{ "yes" } & \multicolumn{3}{|c|}{ "no" } \\
\hline “job”|"member" & "all" & "some" & "none" & "all" & "some" & "none" \\
\hline “adhrm” & 0.212 & 0.268 & 0.322 & 0.358 & 0.427 & 0.489 \\
\hline “tech" & 0.130 & 0.171 & 0.213 & 0.243 & 0.302 & 0.360 \\
\hline "none" & 0.350 & 0.419 & 0.478 & 0.516 & 0.587 & 0.642 \\
\hline
\end{tabular}

Note: Refer to "Data for RQ3" for the meaning of each variable.

In general, the creativity factor appeared to significantly contribute to the chance of both extant and prospective entrepreneurs to generate the first dollar of revenue, especially within 12 months. The factor also helped reduce the probability of being uncertain about future revenue as seen in the last part of Table 12. In the case of an entrepreneur with no previous work experience, no membership in social networks as an example, the probability of becoming uncertain fell from $68.7 \%$ to $47.9 \%$ for those without and with non-radical creativity, respectively.
Figure 4 from Table D2 shows differences for the control variate of "inno" and "diff" for those who anticipated the first revenue soon and who had already generated revenues. In this case, the entrepreneurs had previous work experience in administration or HRM and were active in many social networks.

The creativity factor "inno" clearly has a stronger influence to increased probabilities of having revenues now. But non-radical creativity is seen to be more influential to those to anticipate revenues in near term (but not now). 
Table 12

Probabilities of time to the first dollar revenue conditional upon past experience, social network membership and non-radical creativity factor ("diff")

\begin{tabular}{|c|c|c|c|c|c|c|}
\hline "tot1strev" & \multicolumn{6}{|c|}{ "now" } \\
\hline “diff” & \multicolumn{3}{|c|}{ "yes" } & \multicolumn{3}{|c|}{ "no" } \\
\hline “job”|"member" & "all" & "some" & "none" & "all" & "some" & "none" \\
\hline "adhrm" & 0.179 & 0.147 & 0.110 & 0.123 & 0.097 & 0.068 \\
\hline "tech" & 0.277 & 0.236 & 0.184 & 0.212 & 0.173 & 0.128 \\
\hline "none" & 0.082 & 0.065 & 0.046 & 0.049 & 0.037 & 0.025 \\
\hline "tot1strev" & \multicolumn{6}{|c|}{ "soon" } \\
\hline "diff" & \multicolumn{3}{|c|}{ "yes" } & \multicolumn{3}{|c|}{ "no" } \\
\hline “job”|"member" & “all” & "some" & "none" & "all" & "some" & "none" \\
\hline "adhrm" & 0.602 & 0.587 & 0.567 & 0.471 & 0.436 & 0.397 \\
\hline “tech” & 0.588 & 0.594 & 0.600 & 0.510 & 0.493 & 0.472 \\
\hline "none" & 0.557 & 0.519 & 0.475 & 0.376 & 0.333 & 0.288 \\
\hline "tot1strev" & \multicolumn{6}{|c|}{ "not sure" } \\
\hline "diff" & \multicolumn{3}{|c|}{ "yes" } & \multicolumn{3}{|c|}{ "no" } \\
\hline "job”|"member" & "all" & "some" & "none" & "all" & "some" & "none" \\
\hline "adhrm" & 0.219 & 0.266 & 0.323 & 0.406 & 0.467 & 0.535 \\
\hline "tech" & 0.135 & 0.170 & 0.216 & 0.278 & 0.334 & 0.400 \\
\hline "none" & 0.361 & 0.416 & 0.479 & 0.575 & 0.63 & 0.687 \\
\hline
\end{tabular}

Note: Notes: Refer to "Data for RQ3" for the meaning of each variable.

\section{Discussion}

As all research does, this study has limits but also sparked ideas for potential future examination.

Any self-report survey has limitations. In a country like Vietnam, such surveys are necessary because objective quantitative data of this nature is non-existent. The problem, though, is the difficulty of replication or compare with other countries' entrepreneurship research, at least at present. Entrepreneurship is a young topic Vietnam but is happening very rapidly, so it is important to begin some sort of documentation.

As the field grows in this developing economy, there is also the hope that perhaps the process and approach to research will evolve and therefore see this as a possible area for contribution. Specifically, this raises questions: Is there a way for researchers in early stages of the development of a topic in a given site to take on the research and move up the learning curve faster? Further, are there models that may emerge from developing country research on entrepreneurship and creativity that are different from what has come out of more developed regions?
Future research may also tap some areas that could be useful within and beyond Vietnam. For example, has history played a role in whether some regions are more or less "entrepreneurial?" Some argue that the American presence in the southern region of Vietnam for 25 years may have residual effects for business and entrepreneurship. Does that seem to hold over 50 years later? In essence, are there differences in entrepreneurs' perceptions about starting new firms and about creativity that may vary based upon geographic location or upon industry type?

Another aspect that may affect transition economies in particular (and as Cuba becomes more open for study, it could be an earlier stage site to examine) is the question of what the country gains and loses as its economy changes (Vuong \& Napier, 2015). The example of increased pollution with the rise of vehicles and industrial production is highly evident in China and is becoming more prevalent in Vietnam. But what else may be affected-socially, culturally, politicallywith the increased focus on new ventures and business? In addition, how are organizations affected if creativity and innovation do become more widespread? Many of Vietnam's firms have been, to date, quite hierarchical, suggesting that 
leaders must "know the answers." If creativity is to happen, ideas might emerge from all areas of an organization but will the traditional management style squelch them? If children begin to learn about creativity in school, and bring it into the workplace, will entrepreneurs and other managers be ready to adapt and incorporate different ways of thinking?

The topics of entrepreneurship and creativity in Vietnam-and other emerging and transition economieswill be fascinating to investigate over the next decade.

\section{References}

Agresti, A. (2013). Categorical data analysis (3rd ed.). Hoboken, NJ: Wiley.

Audretsch, D. B., \& Link, A. N. (2012). Entrepreneurship and innovation: Public policy frameworks. Journal of Technology Transfer, 37(1), 1-17.

Basadur, T. M., \& Basadur, M. (2013). Creative problem solving style and individuals' advice network formation and creative performance. Academy of Management Proceedings 2013, No. 1, 17227.

Basadur, M., Gelade, G., \& Basadur, T. (2014). Creative problem-solving process styles, cognitive work demands, and organizational adaptability. The Journal of Applied Behavioral Science, 50(1), 80-115.

Fillis, I., \& Rentschler, R. (2010). The role of creativity in entrepreneurship. Journal of Enterprising Culture, 18(1), 49-81.

Frank, M. W. (1998). Schumpeter on entrepreneurs and innovation: A reappraisal. Journal of the History of Economic Thought, 20(4), 505-516.

Harryson, S. J. (2008). Entrepreneurship through relationships-navigating from creativity to commercialization. REDD Management, 38(3), 290-310.

Ireland, R. D., Hitt, M. A., \& Sirmon, D. G. (2003). A model of strategic entrepreneurship: The construct and its dimensions. Journal of Management, 29(6), 963-989.

Jaussy, K. S., \& Randel,A.E. (2014). Where to look? Creative self-efficacy, knowledge retrieval, and incremental and radical creativity. Creativity Research Journal, 26(4), 400410.
Napier, N. K., Vu, D. L. N., \& Vuong, Q. H. (2012). It takes two to tango: Entrepreneurship and creativity in troubled times-Vietnam 2012. Sociology Study, 2(9), 662-674.

Napier, N. K., \& Vuong, Q. H. (2013). Serendipity as a strategic advantage. In T. J. Wilkinson (Ed.), Strategic Management in the 21st Century (Vol. 1) (pp. 175-199). Santa Barbara, CA: Praeger.

Perry-Smith, J. E., \& Shalley, C. E. (2003). The social side of creativity: A static and dynamic social network perspective. Academy of Management Review, 28(1), 89106.

Runco, M. A. (1994). Problem finding, problem solving, and creativity. Norwood, NJ: Greenwood Publishing Group.

Runco, M. A. (2014). Creativity: Theories and themes: Research, development, and practice. San Diego, CA: Elsevier.

Runco, M. A., \& Jaeger, G. J. (2012). The standard definition of creativity. Creativity Research Journal, 24(1), 92-96.

Vuong, Q. H. (2015). Be rich or don't be sick: Estimating Vietnamese patients' risk of falling into destitution. SpringerPlus, 4(1), No. 529. DOI:10.1186/s40064-0151279-x.

Vuong, Q. H., \& Napier, N. K. (2014a). Resource curse or destructive creation in transition: Evidence from Vietnam's corporate sector. Management Research Review, 37(7), 642-657.

Vuong, Q. H., \& Napier, N. K. (2014b). Making creativity: the value of multiple filters in the innovation process. International Journal of Transitions and Innovation Systems, 3(4), 294-327.

Vuong, Q. H., \& Napier, N. K. (2015). Acculturation and global mindsponge: An emerging market perspective. International Journal of Intercultural Relations, 49, 354367.

Vuong, Q.H.,Napier,N.K., \&Tran,T.D.(2013).A categorical data analysis on relationships between culture, creativity and business stage: The case of Vietnam. International Journal of Transitions and Innovation Systems, 3(1), 4-24.

Ward,T.B.(2004).Cognition, creativity, and entrepreneurship. Journal of Business Venturing, 19(2), 173-188.

Woodman, R. W., Sawyer, J. E., \& Griffin, R. W. (1993). Toward a theory of organizational creativity. Academy of Management Revierw, 18(2), 293-321. 